\title{
Excitation of back-arc tsunamis from megathrust ruptures: The underdog hazard in the Sea of Japan
}

\author{
Amir Salaree ${ }^{\dagger} \&$ Yihe Huang* \\ Department of Earth \& Environmental Sciences \\ University of Michigan \\ ${ }^{\dagger}$ salaree@umich.edu \\ *yiheh@umich.edu
}

20

June 29, 2021

25

30

for submission to

This is a non-peer reviewed preprint submitted to EarthArXiv. 


\begin{abstract}
The 2011 Tohoku earthquake created a moderate tsunami in the back-arc Sea of Japan basin. This tsunami went largely unnoticed due to its small size and the significant coverage of the large fore-arc waves. We present a physical dislocation model for the excitation of back-arc tsunamis and identify fault dip as the main geometrical contributor to the propagation of back-arc tsunamis. Using numerical simulations and data from the 2011 event, we show that a

45 combination of near- to intermediate-field horizontal and vertical dislocations as well as transient surface waves is necessary to reconstruct the back-arc propagation. We then simulate potential future earthquakes in the Japan trench and Nankai trough to investigate the back-arc tsunami hazard in the Sea of Japan. Our results show that the coseismic excitation of back-arc tsunamis can result in considerable waves exceeding $1 \mathrm{~m}$ from megathrust earthquakes.
\end{abstract}

40

50 


\section{Plain Language Summary}

The 2011 Japan earthquake also created a tsunami in the Sea of Japan, i.e., the backyard of Japan basin. This tsunami was generated directly by the deformation of sea floor caused by

55 the 2011 Japan earthquake, but not by the Pacific tsunami waves turning around the Japanese islands. This tsunami went largely unnoticed due to its small size and the significant coverage of the tragic large fore-arc waves. Here, we present a model incorporating the instantaneous deformation from earthquake as well as surface waves to explain the generation of such tsunamis on the far side of narrow continents. We show that the vertical angle of a fault has a significant

60 effect on how the tsunami propagates to the far side seas and oceans. We use these findings to evaluate the tsunami hazard in the Sea of Japan from large earthquakes in eastern and southern Japan.

$65 \quad$ Key Points:

- Back-arc tsunamis are important sources of hazard in tectonic back-arc basins such as the Sea of Japan.

- Rayleigh waves contribute to the tsunamis in the back-arc basins, especially in the absence of large static deformation.

- Fault dip is the most important source parameter affecting the span of back-arc tsunamis from megathrust events with the same magnitude. 


\section{Introduction}

The $2011 \mathrm{Mw} 9.0$ Tohoku earthquake ruptured a $\sim 200 \mathrm{~km} \times \sim 400 \mathrm{~km}$ patch of the Pacific-Okhotsk plate boundary along the Japan trench [Ammon et al, 2011; Ide et al, 2011; Shao et al, 2011; Lay, 2018] with unusually large slip, up to 50-80 m [Fujiwara, 2011; Ito et al, 2011a]. The shallow hypocenter at $25 \mathrm{~km}$ [Dziewonski et al, 1981; Ekström et al, 2012] combined with the large slip resulted in ocean floor uplifts of up to $\sim 5 \mathrm{~m}$ near the coastline, as

80 well as $\sim 30 \mathrm{~m}$ vertical and $\sim 60 \mathrm{~m}$ horizontal displacements at the trench, respectively [Kido et al, 2011, Ito et al, 2011b]. The large areas of uplift and subsidence at the ocean floor [Grapenthin \& Freymueller, 2011] generated a devastating tsunami reaching $40 \mathrm{~m}$ along the Sanriku coast [Mori et al, 2011; Shimozono et al, 2012].

However, the coseismic deformation was not limited to the trench side of the Japan

85 island - the fore-arc. In fact, geodetic measurements documented decimetric and centimetric deformations in the western Japanese coastlines [Pollitz et al, 2011]. This so-called back-arc field of deformation would continue into the Sea of Japan and result in a complex pattern of uplift and subsidence at the sea floor. Numerical models also successfully predict centimetric deformation westward across the Sea of Japan reaching Russia [Pollitz et al, 2011; Sato et al,

90 2011]. Such back-arc deformations are expected from Okada algorithms for a buried, inclined fault plane (Fig. 1). 


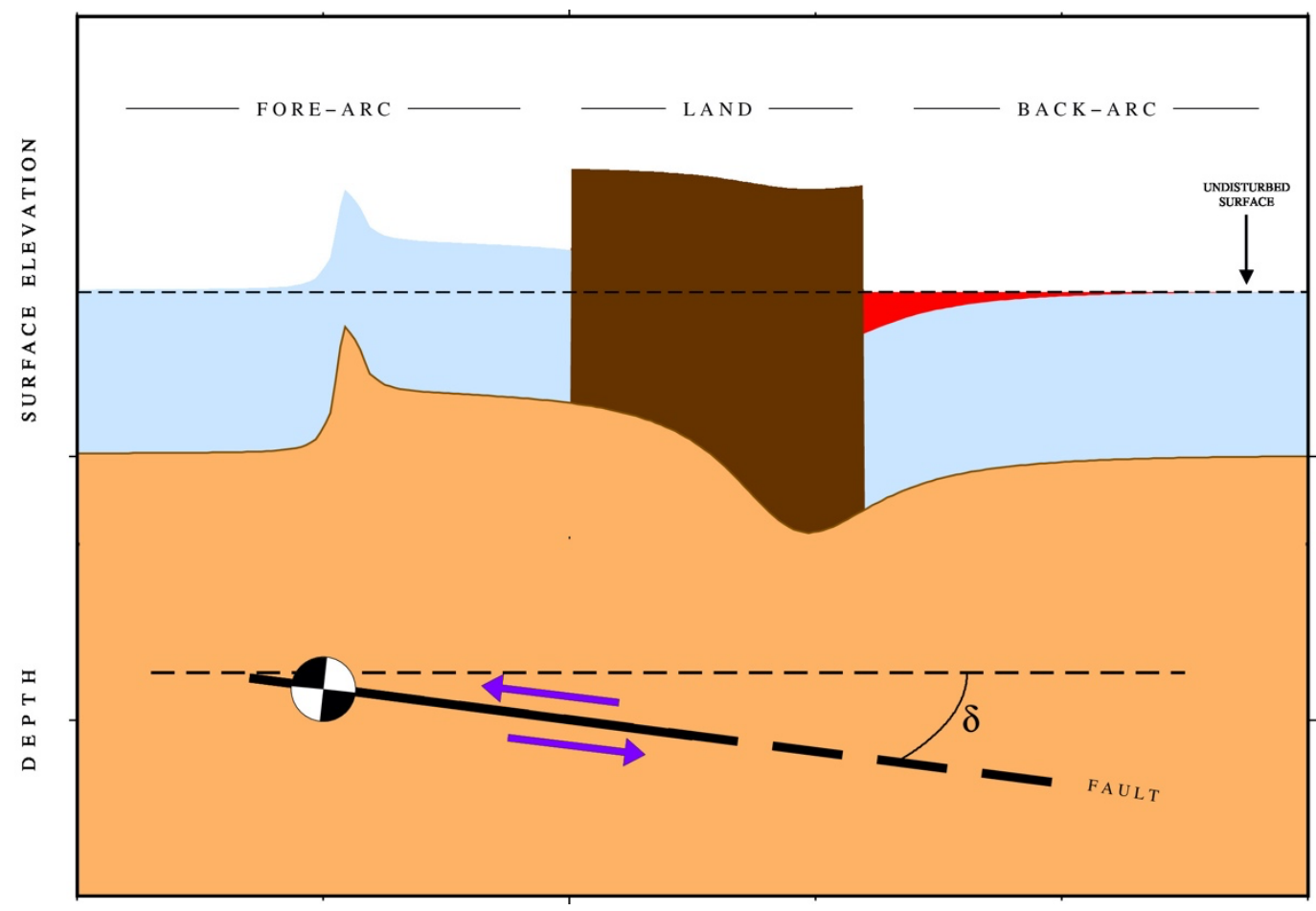

Figure 1. Along-dip cross-section of the dislocation model. Beachball represents rupture hypocenter. Purple arrows denotes down-dip fault motion. Ocean floor and water are shown in orange and blue, respectively. Back-arc displaced volume of water is depicted in red. $\delta$ represents fault dip. as recorded by tide gauges around the Sea of Japan. Small waves were also reported by local fishermen at Niigata Prefecture [Murotani, personal. comm.]. Murotani et al [2015] showed that the arrival times of these tsunami waves matched the origin time of earthquake centroid and hence were excited coseismically. They modeled this tsunami using both vertical and horizontal components from a point source using Okada's [1985] algorithm.

Here we further investigate the characteristics of back-arc tsunamis in the Sea of Japan by considering the effects of surface waves from the mainshock in addition to static dislocations. We also evaluate the back-arc tsunami hazard from various megathrust earthquakes in the Japan 
trench and Nankai Trough. We show that considerable $(\sim 1 \mathrm{~m})$ back-arc coastal amplitudes in the

105 Sea of Japan are possible from such events. Finally, we provide a simple physical model for the generation of back-arc tsunamis highlighting the most important source parameters involved.

\section{Data and Method}

\subsection{Tide gauge data}

To investigate the propagation of the 2011 back-arc tsunami, we use data from three tide gauges along the western coastlines in Rudnaya Pristan, Preobrazheniye (both in Russia), Busan (Korea), as well as five tide gauges from Geospatial Information Authority of Japan (GSI) on the Japanese coast (Fig. 2a). These stations provide a reasonable coverage of the tsunami around the

115 Sea of Japan. The Busan station is used to analyze the critical interaction of fore- and back-arc arrivals. The time series from Russian and Japanese sites are sampled at 1-minute and 30-second intervals, respectively.

\subsection{Tsunami Simulation}

We apply the algorithm by Mansinha \& Smylie [1971] to calculate vertical and horizontal deformations as initial conditions for tsunami simulations. We use the MOST algorithm [Titov et al, 2016] to simulate the tsunamis and truncate the simulations at a shallow depth $(10 \mathrm{~m})$ close to the coastline. MOST has been extensively validated and applied in tsunami studies [Synolakis et al, 2008]. Our simulations are carried out using the ETOPO2 bathymetry 
125 grid with a resolution of 2 arc-minutes, and over 24-hr time windows with $5 \mathrm{~s}$ time steps to satisfy the CFL stability conditions.

\subsection{Contribution of surface waves}

Surface waves from earthquakes can cause tsunamis and seiches for various basin types 130 due to their high amplitudes and wide spectral range [Barberopoulou, 2004; Saito et al, 2019]. Our simulations consider the initial deformation from Rayleigh waves which typically possess higher frequency content than the longer period tsunami waves. Using a normal modes approach, we calculate surface wave eigenfunctions down to $\sim 150$ seconds (see supplementary material). This corresponds to a spatial resolution of $\sim 30 \mathrm{~km}$ in the Sea of Japan, which is shallower than $1354000 \mathrm{~m}$, and should be sufficient considering the large source dimensions.

\section{Simulation Results}

We carry out tsunami simulations using (a) vertical deformation, (b) both vertical and horizontal deformations for the CMT solution, and (c) a combination of surface deformation and Rayleigh waves (more details are shown in supplementary material). Fig. 2a shows the simulation result from the superposition of all three deformation sources as initial conditions. Each panel in Fig. 2(b-d) shows the simulated time series compared to recorded data (black curves) as well as their correlation coefficients for 1-hr time intervals (results for a longer simulation window are shown in Figs. S1 \& S2). 
Similar to this study, Murotani et al [2015] were more successful in matching the observed signals from stations at the far side of the Sea of Japan (see supplementary material). The discrepancy is possibly due to the effect of bathymetry caused by horizontal component. We attribute the practically non-existing coseismic amplitudes and the signal complexity in Busan [similar issues can be seen at Okushiri in the north (Fig. 2)] to its proximity to deformation node

150 (Figs. 3a and 3c). Beamforming of tsunami waves in the Korea Strait shows that the slower backarc waves (from the shallow continental shelf) arrive at Busan only slightly earlier than the faster fore-arc waves (from the deep trench). The flip-flops in the dominant azimuth of arriving tsunami waves near Busan shows significant changes in the propagation direction as well as the influence of large-scale reflections (Figs. S4 and S5). Thus, the first arrival is an emergent phase 155 with negative polarity (edge waves from the nearby coseismic coastal depression in the backarc). Later on, this signal mixes with the positive polarity, fore-arc signal in a complex pattern, hence resulting in the poor fit of the simulations. This underlines the importance of source geometry in excitation of back-arc tsunamis. 

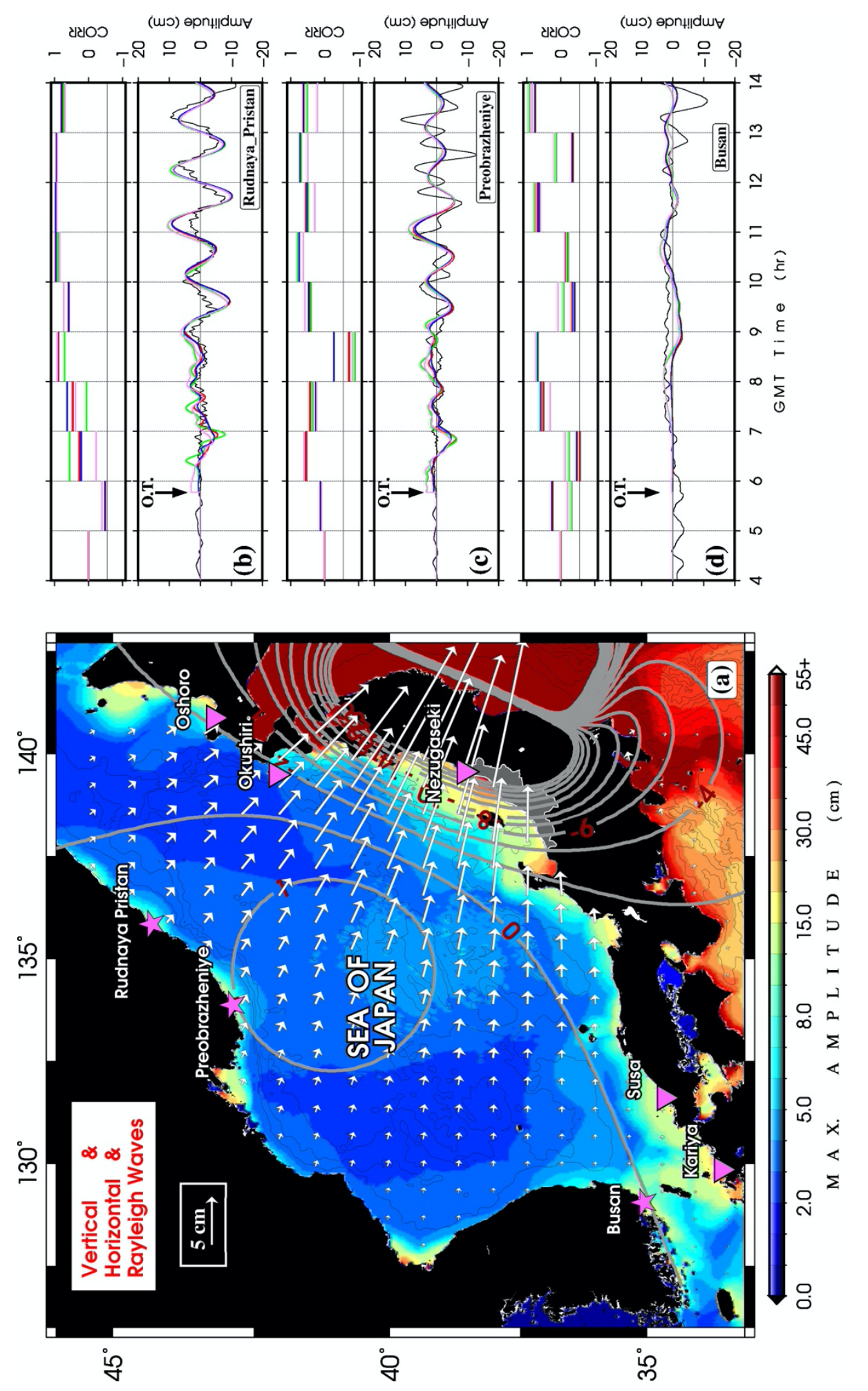


\section{Potential Back-arc Tsunami Hazard in the Sea of Japan}

The tectonic convergence at the Japan Trench and the Nankai Trough has resulted in multiple documented megathrust events in the east and south of Japan. Subduction patches capable of hosting similar megathrust events have been studied in detail along both margins

165 [Ando, 1975; Furumura et al, 2011; Satake, 2015; Kusumoto, 2018]. We use the proposed rupture locations and geometries from previous studies as potential future sources that are large enough to produce back-arc tsunamis in the Sea of Japan. Here, we do not include surface waves in the simulations as we are mainly investigating the largest amplitudes, not the first, high frequency portion of tsunamis.

\subsection{Japan Trench}

The subduction zone along the Japan trench can be considered as a set of potential rupture patches in an interwoven pattern [Satake, 2015]. A successive cascade of ruptures on these fault patches can occur during a single large megathrust, similar to the 2011 Tohoku event

175 [Stein \& Okal, 2011; Noda \& Lapusta, 2013]. As a given paleoseismic window may not capture long-term trends in seismicity [Salditch et al, 2020], such large rupture areas can be keys to understanding the maximum possible earthquake and tsunami hazards.

We construct a composite rupture area by joining the previous $\mathrm{M}_{\mathrm{S}}$ 7.1-7.8 events in 1936, 1937, 1938 and 1978 in the Miyagi-oki sequence, spanning a total geographic area of $\sim 300 \mathrm{~km} \times$ $\sim 150 \mathrm{~km}$ (Abe, 1977; Umino, 2006; Satake, 2015), i.e., roughly 50\% of the 2011 mainshock 
rupture area. We replace the 1936 event with its collocated 2005 counterpart because of better data (Table S2). Then using earthquake scaling laws [Geller, 1976] for a constant stress drop and assuming a uniform convergence rate along the trench, we calculate an average slip and magnitude $\left(\mathrm{M}_{\mathrm{w}}=8.8\right)$ for this earthquake, scaled down from the 2011 Tohoku as reference (the

185 Tohoku event has a Kagan aperture [Kagan, 1991] of $\sim 23^{\circ}$ from the total mechanism obtained from the events in the sequence). We also make another composite source with similar geometry, but a moment identical to 2011 Tohoku (Figs. 3a and 3b; see the supplementary material for source details and simulations). These simulations show while the back-arc propagation patterns of the composite sources are fairly similar $(\mathrm{CC}=0.55)$, the maximum tsunami amplitudes from 190 the large source is twice as large as the smaller event, reaching $1.7 \mathrm{~m}$.

\subsection{Nankai Trough}

While $M>8$ earthquakes have been frequently documented in Nankai Trough [Ishibashi, 2004], M 9 events are also deemed possible through joining all the segments in single large ruptures [Yokota et al, 2016]. We simulate back-arc tsunamis in the Sea of Japan for five rupture scenarios using combinations of the blocks proposed by Furumura et al [2011]. Simulation results for the largest possible rupture are shown in Figs. 3c and 3d (see the supplementary material for more details). Fig. $3 \mathrm{~d}$ shows that earthquakes in the Nankai Trough would generate small tsunamis in the Sea of Japan; an almost 3 times smaller source $\left(\mathrm{M}_{\mathrm{w}}=8.8\right.$; model IV in Fig.

200 S6) with a similar rupture length, produces tsunami amplitudes barely exceeding $15 \mathrm{~cm}$ in the back-arc (Fig. S6j). 

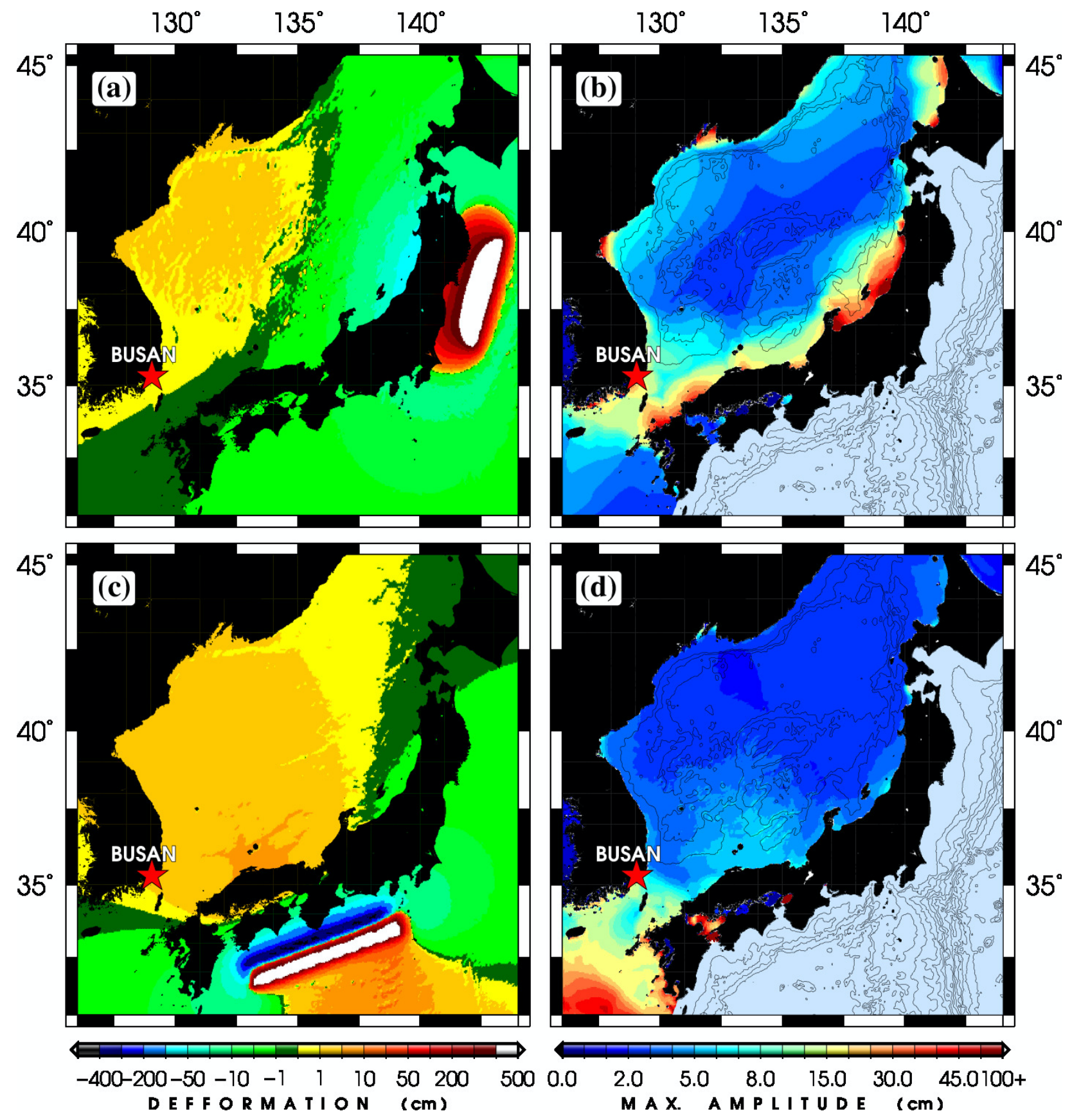

Figure 3. (a) Static, coseismic field deformation from the conglomerate source in the Japan trench with the same seismic moment as 2011 Tohoku. (b) Simulated back-arc tsunami from (a). (c) Deformation field from the largest speculated source in the Nankai Trough. (d) Simulated back-arc tsunami from (c). 


\section{Parameters Controlling the Back-arc Tsunami}

Here we investigate the effects of bathymetry, surface waves and earthquake source parameters in the excitation and propagation of back-arc tsunamis.

\subsection{Bathymetry \& Surface Waves}

As discussed in section 4, bathymetry has a significant role in the higher frequency content of back-arc tsunamis. This effect is more noticeable in the presence of smaller

210 deformation, e.g., in the case of Busan where the 2011 tsunami arrived more than one hour later than the Russian sites (Figs. 2b-d). Ray-tracing experiments (supplementary material) confirm that the Japanese sites as well as Busan experience considerably more complex wavefronts than those on the far side of the Sea of Japan, due to the entrapment of tsunami energetics in the complex southern bathymetry (Fig. S7).

Our results in section 2.3 show that the contribution of Rayleigh waves to the 2011 Tohoku back-arc tsunami at near- to intermediate-field locations may be important, as their addition slightly improves fits to the observed signal ( $30 \%$ increase in $\mathrm{CC})$ at higher frequencies (during the first few hours of the records after origin time) in Rudnaya Pristan but not in Preobrazheniye (see between 6-7 hrs in Fig. 2b). While these stations are approximately in the same radiation lobe of Rayleigh waves, the inconsistency may be due to rupture directivity.

\subsection{Earthquake source}

The extent to which each earthquake source parameter affects the back-arc tsunami is yet to be discussed. Fig. 1 is a simple cross-section of what we consider as the back-arc 
deformation model. This model is based on the general Okada solution for a centroid near the

225 trench in the fore-arc. Such models are routinely used in tsunami simulations due to their simplicity and robustness [Titov \& Synolakis, 1998; Okal \& Synolakis, 2004]. In Fig. 1, the earthquake epicenter and mechanism shown by a beachball is located on a fault plane depicted as an inclined, solid black line with a dip angle of $\delta$, turning into a dashed line to imply the uncertainty in the extent of down-dip rupture propagation.

In the absence of bathymetry, the deformed ocean floor in Fig. 1 (shown in orange) displaces a body of water from static coseismic deformation in the back-arc (shown in red). It is the geographic span and volume of this amount of water that results in back-arc tsunamis, and consequently the source parameters contributing the most to back-arc tsunamis are those increasing this volume.

Naturally, earthquakes with higher seismic moment (i.e., larger ruptures) or closer to land would create larger back-arc tsunamis as they would displace more water on the opposite side of the continent. However, as large $(\mathrm{M}>8.5)$, shallow $(\mathrm{H}<30 \mathrm{~km})$ thrust earthquakes capable of generating large back-arc tsunamis are mainly expected to happen at or in the vicinity of trenches, the most loosely constrained source parameter will be source geometry. Megathrusts 240 tend to occur at shallow dips $\left(\delta<30^{\circ}\right)$ and slip vectors almost perpendicular to the trench $\left(45^{\circ}<\lambda<135^{\circ}\right)$

To investigate the influence of source geometry (focal mechanism) and depth, we design and carry out tsunami simulations in a fore-arc_-back-arc system as shown in Fig. 4. In these synthetic scenarios, a deep fore-arc $(4000 \mathrm{~m})$ is separated from a relatively shallow back-arc $245(1000 \mathrm{~m})$ by a narrow $(\sim 50 \mathrm{~km})$ continent. The source scenarios are assigned a seismic moment 
of $4.0 \times 10^{29}$ dyn-cm $\left(\mathrm{M}_{\mathrm{w}}=9.0\right)$ and are placed in the fore-arc, next to the continent ( $75 \mathrm{~km}$ away) at a central latitude (green stars in Fig. 4). Each scenario is designed as a set of $(H, \delta, \lambda)$ (i.e., depth, dip, and slip) with $10 \mathrm{~km} \leq H \leq 40 \mathrm{~km}, 10^{\circ} \leq \delta \leq 40^{\circ}$, and $40^{\circ} \leq \lambda \leq 90^{\circ}$ (benefiting from the axial symmetry along latitude) while keeping the rupture strike the same as that of the trench, 250 assumed to be parallel to the continental arc. 


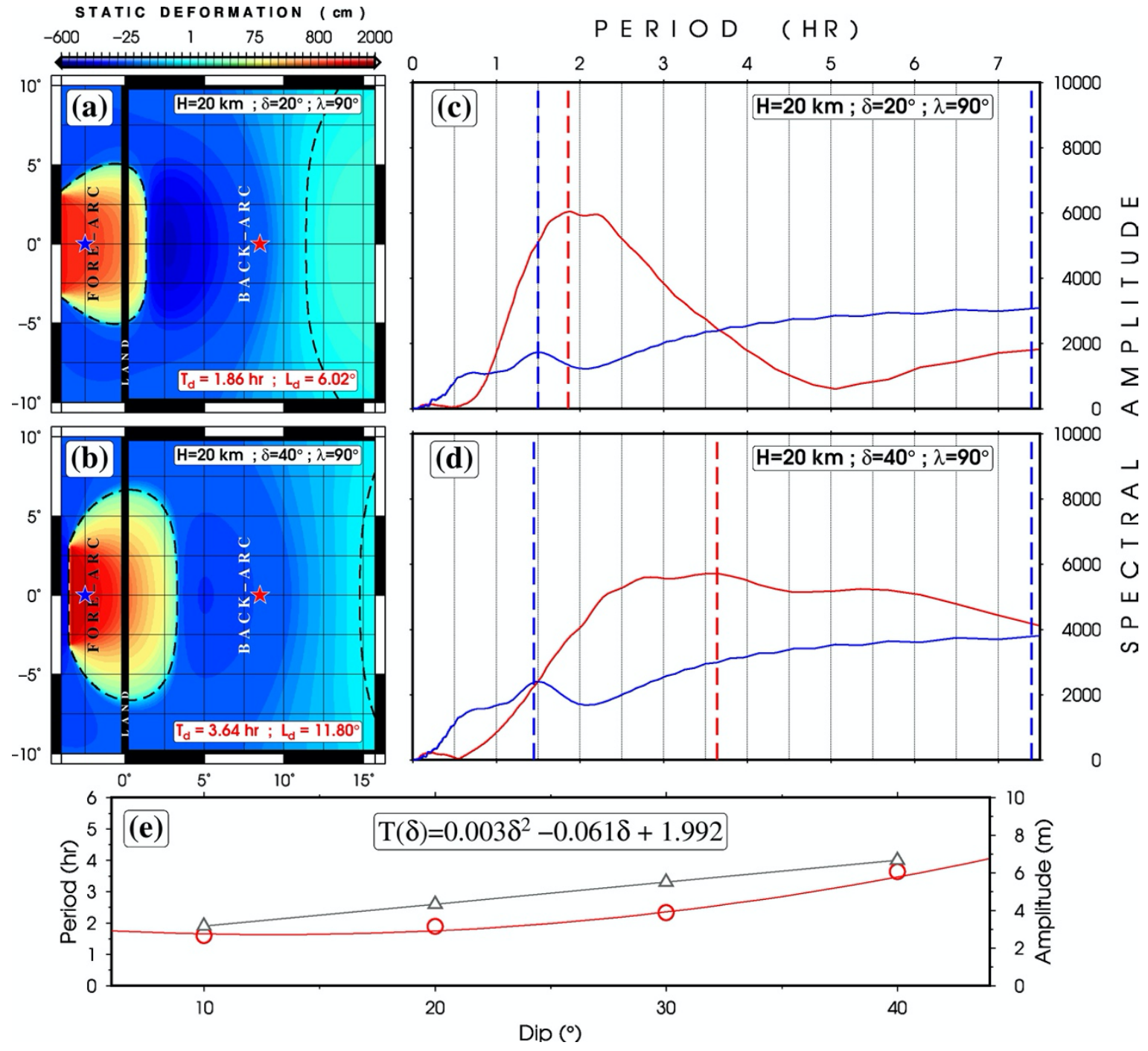

Figure 4. (a),(b) Ocean floor deformation fields calculated from $M_{w} 9.0$ point sources in the forearc for two dip angles. Black, dashed lines show the deformation nodes (i.e., zero deformation). In each panel, dominant tsunami periods from numerical simulations $\left(\mathrm{T}_{\mathrm{d}}\right)$ and the corresponding length scale $\left(\mathrm{L}_{\mathrm{d}}\right)$ to those periods are listed. (c),(d) Spectra of the simulated tsunamis at two virtual gauges for the corresponding scenarios in (a) and (b). The blue and red curves are from gauges in the fore- and back-arc, respectively [blue and red stars in (a) and (b)]. Dashed lines show spectral maxima of the curves with the same color. (e) Variations in dominant period (red) and maximum amplitude (gray) in the back-arc as functions of dip angle for $M_{w}=9.0$ sources at $H=20 \mathrm{~km} ; T(\delta)$ is the equation for the fit to dominant periods. 
We calculate coseismic, static deformation fields extending from the source into the 255 back-arc basin. Figs. $4 \mathrm{a}$ and $4 \mathrm{~b}$ show two examples of these scenarios where the source is at a depth of $20 \mathrm{~km}$ and has a slip angle perpendicular to the strike of the thrust fault $\left(\lambda=90^{\circ}\right)$. The different dip angles in Fig. $4 \mathrm{a}\left(\delta=20^{\circ}\right)$ and $4 \mathrm{~b}\left(\delta=40^{\circ}\right)$ result in different fields of surface deformation in the back-arc. We then carry out tsunami simulations in both sides of the narrow continental arc for a semi-closed (opening on the right) basin. Figs. $4 \mathrm{c}$ and $4 \mathrm{~d}$ show spectral amplitudes of the tsunami time series recorded at two virtual gauges in the fore- and back-arc basins of the scenarios in Figs. $4 \mathrm{a}$ and $4 \mathrm{~b}$. The frequency band in Figs. $4 \mathrm{c}$ and $4 \mathrm{~d}$ is selected to avoid fundamental resonance modes in the basin (supplementary material).

As shown in Figs. 4c and 4d, the spectra of the tsunami in semi-closed (red) back-arc basin are significantly different from those at the fore-arc (blue) gauge, while the difference 265 between the fore-arc spectra in Figs. $4 \mathrm{c}$ and $4 \mathrm{~d}$ is very small. This shows that though the foreand back-arc signals are excited by common sources they have very different frequency contents and thus are essentially different [Rabinovich, 1997]. This is particularly noteworthy in the dominant period, $T_{d}$, of back-arc tsunamis.

Our simulations show that contrary to fore-arc tsunamis [Rabinovich, 1997; Abe, 2006], 270 the dominant periods of back-arc waves are not directly determined by fault width which is usually taken as a fraction of the fault length. On the other hand, fault dip seems to determine the dominant period (Table S3). This relationship is a quadratic function of dip angle, leading to often longer period signals (Fig. 4e). By controlling the vertical distance to the buried fault in the back-arc, $H_{b}$, i.e., a secondary fault depth $\left(H_{b}=W \cdot \sin \delta\right.$, with $W$ as fault width), dip angle $\delta$

275 controls the excitation depth of these waves, and therefore their dominant period. The relationship is further compounded by the effect of dip angle on the geographic extent and thus 
the perturbed water volume in the back-arc. In other words, the back-arc part of deformation in the direction perpendicular to the arc, can be defined as an effective length controlling the displaced water volume, and hence the tsunami. We also find that the dominant back-arc

280 frequency is invariant of fault slip angle (Table S3).

In contrast to fore-arc tsunamis wherein larger dip angles result in higher tsunami amplitudes (Titov et al, 1999), back-arc tsunami amplitudes follow a complex trend. For smaller sources $\left(M_{w}<9.0\right)$, the variations of amplitude against changes in dip angle is not uniform (Fig. S8), because the back-arc basin samples mostly the smaller, negative part of vertical deformation

285 from the megathrust, mixed by a part (if any) of positive portion of the field, depending on dip angle and source depth (Fig. S9a,b). For larger sources $\left(\mathrm{M}_{\mathrm{w}} \geq 9.0\right)$, however, the buried fault approaches the surface and due to larger values of slip, the back-arc experiences larger vertical components (both area and amplitude), accompanied by insignificant changes to the deformation pattern (Figs. 4e, S8, and S9c,d). In fact, simulations show higher back-arc amplitudes for 290 sources with larger dip angle for such large sources (Figs. 4e).

\section{Discussion \& Conclusion}

Our simulations of back-arc tsunamis in the Sea of Japan form the 2011 Tohoku rupture confirm Murotani et al's [2015] conclusion on the significant contribution of horizontal

295 deformation. In addition, we find that the contribution of Rayleigh waves to back-arc tsunami amplitudes, especially in the case of small static deformations, must be taken into account. At nodal stations, addition of surface waves would potentially improve the quality of simulations, 
especially at higher (although low amplitude) frequencies. This is best demonstrated in the case of Busan which was located at a deformation node of the 2011 Tohoku event. trench reveal the potential of back-arc tsunamis with coastal amplitudes reaching more than $1 \mathrm{~m}$ in western Japan and up to $\sim 50 \mathrm{~cm}$ on the far side of the Japan Sea. While such amplitudes are very small compared to the fore-arc run-up values ( $>20 \mathrm{~m}$ close to the epicenter) and often ignored in the wake of fore-arc catastrophes, they must be taken seriously in a basin which is 305 otherwise deemed as safe from tsunamis. We emphasize that the reported coastal amplitudes from the simulations in this study are at a distance from the coastlines and are thus smaller than run-up [Synolakis, 1991]. In other words, the on-land tsunami amplitudes will be relatively larger than our calculations while following similar along-coast patterns.

Simulation of tsunamis from potential sources in the Nankai Trough leads to similar 310 results, albeit on a smaller scale. We attribute this deficiency of back-arc tsunami amplitudes (compared to the cases in Japan trench) to the wider continental arc as well as a large shallow continental shelf in the southern back-arc. Note that even the largest Nankai scenario, i.e., Fig. $3 \mathrm{c}-\mathrm{d}$ (model V in Table S1) only succeeds in creating moderate amplitudes on a local scale. While such amplitudes barely exceed $15 \mathrm{~cm}$, they may pose hazard to the coastal communities in 315 bays and harbors [Abe, 2006]. Similar to the case of ruptures in Japan Trench, small coseismic amplitudes in Korea are due to the close proximity of deformation nodes.

Megathrust events tend to occur in shallow depths $(<40 \mathrm{~km})$ with the majority of accumulated strain released within the crust and close to the trench. Although as a global average, trenches are located $\sim 250 \mathrm{~km}$ away from continents, depending on the shape, size and 
320 physical properties of the megathrust zone, these ruptures can take place only slightly closer to land [Bilek \& Lay, 2018]. Therefore, the magnitudes of megathrusts determine the extent of down-dip faulting and thus that of back-arc deformation (see Fig. 1).

At a constant magnitude $\left(\mathrm{M}_{\mathrm{w}}=9.0\right)$, our results show that among the geometrical source parameters, dip angle $(\delta)$ has the most significant contribution and determines the dominant

325 frequency of back-arc tsunamis. We also find that ruptures with larger dip angle create more widespread back-arc tsunamis - this can readily be seen in our simulation of the potential source near Honshu [see Table S2] whose larger dip angle compared to 2011 Tohoku leads to a larger back-arc tsunami (Fig. S11). Thus, large megathrust earthquakes $\left(\mathrm{M}_{\mathrm{w}} \geq 9.0\right)$ with large dip angles $\left(>20^{\circ}\right)$ are expected to create larger back-arc tsunamis. Based on this model, the effective length 330 calculated as the extent of back-arc depression in a direction perpendicular to the trench determines the main properties of back-arc tsunamis. While larger ruptures result in slip fields closer to surface, hence producing more significant surface deformation, the focal depth of such events does not seem to have a significant impact (Fig. S8). This simple model can be readily used in subduction zones with back-arc basins around the world. While some regions such as

335 Java seem to be immune to the back-arc tsunami hazard due to the large trench-to-coast distance (an average of $\sim 450 \mathrm{~km}$ ), such hazard needs to be assessed and mitigated in various regions including Alaska, the Philippines, Sumatra (see supplementary material) and Oaxaca. 


\section{Acknowledgement}

The authors are grateful to Satoko Murotani for sharing tide gauge data from the Japanese stations, and for providing accounts of the 2011 Tohoku back-arc tsunami. We also thank Emile Okal for discussions on synthesis of surface waves. The bathymetry data used in this 345 study is publicly available via NOAA [National Geophysical Data Center, 2006]. The tsunami simulation code is maintained and distributed by NOAA. Tide gauge data is available through the Sea Level Station Monitoring Facility (http://www.ioc-sealevelmonitoring.org/map.php) and Geospatial Information Authority of Japan (GSI)

(https://www.gsi.go.jp/kanshi/tide furnish.html). Several figures were created using Generic

350 Mapping Tools [Wessel \& Smith, 1998]. This study was funded by National Science Foundation grant PREEVENTS geosciences directorate No. 1663769.

\section{References}

- Abe, K., 1977. Tectonic implications of the large Shioya-Oki earthquakes of 1938. Tectonophysics, 41(4), pp.269-289.

- Abe, K., 2006. Dominant periods of the 2004 Sumatra tsunami and the estimated source size. Earth, planets and space, 58(2), pp.217-221.

- Ammon, C.J., Lay, T., Kanamori, H. and Cleveland, M., 2011. A rupture model of the 2011 off the Pacific coast of Tohoku Earthquake. Earth, Planets and Space, 63(7), p.33.

$360-$ Ando, M., 1975. Source mechanisms and tectonic significance of historical earthquakes along the Nankai Trough, Japan. Tectonophysics, 27(2), pp.119-140.

- Barberopoulou, A., Qamar, A., Pratt, T.L., Creager, K.C. and Steele, W.P., 2004. Local amplification of seismic waves from the Denali Earthquake and damaging seiches in Lake Union, Seattle, Washington. Geophysical research letters, 31(L03607), 5 pp. 
- Bilek, S.L. and Lay, T., 2018. Subduction zone megathrust earthquakes. Geosphere, 14(4), pp.1468-1500.

- Dziewonski, A. M., T.-A. Chou and J. H. Woodhouse, Determination of earthquake source parameters from waveform data for studies of global and regional seismicity, J. Geophys. Res., 86, 2825-2852, 1981.

370 - Ekström, G., M. Nettles, and A. M. Dziewonski, The global CMT project 2004-2010: Centroid-moment tensors for 13,017 earthquakes, Phys. Earth Planet. Inter., 200-201, 19, 2012.

- Fujiwara, T., Kodaira, S., No, T., Kaiho, Y., Takahashi, N. and Kaneda, Y., 2011. The 2011 Tohoku-Oki earthquake: Displacement reaching the trench axis. Science,

375 334(6060), pp.1240-1240.

- Furumura, T., Imai, K. and Maeda, T., 2011. A revised tsunami source model for the 1707 Hoei earthquake and simulation of tsunami inundation of Ryujin Lake, Kyushu, Japan. Journal of Geophysical Research: Solid Earth, 116(B2).

- Geller, R.J., 1976. Scaling relations for earthquake source parameters and magnitudes. Bulletin of the Seismological Society of America, 66(5), pp.1501-1523.

- Grapenthin, R. and Freymueller, J.T., 2011. The dynamics of a seismic wave field: Animation and analysis of kinematic GPS data recorded during the 2011 Tohoku-oki earthquake, Japan. Geophysical Research Letters, 38(18).

- Ide, S., Baltay, A. and Beroza, G.C., 2011. Shallow dynamic overshoot and energetic deep rupture in the $2011 \mathrm{Mw} 9.0$ Tohoku-Oki earthquake. Science, 332(6036), pp.1426-1429.

- Ishibashi, K., 2004. Status of historical seismology in Japan. Annals of Geophysics, 47(23), pp. 338-369

- Ito, T., Ozawa, K., Watanabe, T. and Sagiya, T., 2011b. Slip distribution of the 2011 off the Pacific coast of Tohoku Earthquake inferred from geodetic data. Earth, planets and 390 space, 63(7), pp.627-630.

- Ito, T., T., Osada, Y., Kido, M., Inazu, D., Hayashi, Y., Tsushima, H., Hino, R. and Fujimoto, H., 2011a. Frontal wedge deformation near the source region of the 2011 Tohoku-Oki earthquake. Geophysical Research Letters, 38(7).

- Kido, M., Osada, Y., Fujimoto, H., Hino, R. and Ito, Y., 2011. Trench-normal variation in observed seafloor displacements associated with the 2011 Tohoku-Oki earthquake. Geophysical Research Letters, 38(24).

- Kusumoto, S., Goto, T., Sugai, T., Omori, T. and Satake, K., 2018. Geological evidence of tsunamis in the past 3800 years at a coastal lowland in the Central Fukushima Prefecture, Japan. Marine Geology, 404, pp.137-146. 
- Lay, T., 2018. A review of the rupture characteristics of the 2011 Tohoku-oki Mw 9.1 earthquake. Tectonophysics, 733, pp.4-36.

- Mansinha, L.A. and Smylie, D.E., 1971. The displacement fields of inclined faults. Bulletin of the Seismological Society of America, 61(5), pp.1433-1440.

- Mori, N., Takahashi, T., Yasuda, T. and Yanagisawa, H., 2011. Survey of 2011 Tohoku earthquake tsunami inundation and run-up. Geophysical research letters, 38(7).

- Murotani, S., Iwai, M., Satake, K., Shevchenko, G. and Loskutov, A., 2015. Tsunami forerunner of the 2011 Tohoku Earthquake observed in the Sea of Japan. Pure and Applied Geophysics, 172(3-4), pp.683-697.

- National Geophysical Data Center, 2006. 2-minute Gridded Global Relief Data (ETOPO2) 410 v2. National Geophysical Data Center, NOAA. doi:10.7289/V5J1012Q [accessed on Oct $5,2020]$

- Noda, H. and Lapusta, N., 2013. Stable creeping fault segments can become destructive as a result of dynamic weakening. Nature, 493(7433), pp.518-521.

- Okada, Y., 1985. Surface deformation due to shear and tensile faults in a half-space.

415 Bulletin of the seismological society of America, 75(4), pp.1135-1154.

- Okal, E.A. and Synolakis, C.E., 2004. Source discriminants for near-field tsunamis. Geophysical Journal International, 158(3), pp.899-912.

- Pollitz, F.F., Bürgmann, R. and Banerjee, P., 2011. Geodetic slip model of the 2011 M9.0 Tohoku earthquake. Geophysical Research Letters, 38(7).

420 - Rabinovich, A.B., 1997. Spectral analysis of tsunami waves: Separation of source and topography effects. Journal of Geophysical Research: Oceans, 102(C6), pp.1266312676.

- Saito, T., Baba, T., Inazu, D., Takemura, S. and Fukuyama, E., 2019. Synthesizing sea surface height change including seismic waves and tsunami using a dynamic rupture 425 scenario of anticipated Nankai trough earthquakes. Tectonophysics, 769, p.228166.

- Salditch, L., Stein, S., Neely, J., Spencer, B.D., Brooks, E.M., Agnon, A. and Liu, M., 2020. Earthquake supercycles and Long-Term Fault Memory. Tectonophysics, 774, p.228289.

- Satake, K., 2015. Geological and historical evidence of irregular recurrent earthquakes in $430 \quad$ Japan. Philosophical Transactions of the Royal Society A: Mathematical, Physical and Engineering Sciences, 373(2053), p.20140375.

- Sato, M., Ishikawa, T., Ujihara, N., Yoshida, S., Fujita, M., Mochizuki, M. and Asada, A., 2011. Displacement above the hypocenter of the 2011 Tohoku-Oki earthquake. Science, 332(6036), pp.1395-1395. 
435 - Shao, G., Li, X., Ji, C. and Maeda, T., 2011. Focal mechanism and slip history of the 2011 M w 9.1 off the Pacific coast of Tohoku Earthquake, constrained with teleseismic body and surface waves. Earth, planets and space, 63(7), pp.559-564.

- Shimozono, T., Sato, S., Okayasu, A., Tajima, Y., Fritz, H.M., Liu, H. and Takagawa, T., 2012. Propagation and inundation characteristics of the 2011 Tohoku tsunami on the $440 \quad$ central Sanriku coast. Coastal engineering journal, 54(01), p.1250004.

- Stein, S. and Okal, E.A., 2011. The size of the 2011 Tohoku earthquake need not have been a surprise. Eos, Transactions American Geophysical Union, 92(27), pp.227-228.

- Synolakis, C.E., 1991. Green's law and the evolution of solitary waves. Physics of Fluids A: Fluid Dynamics, 3(3), pp.490-491.

445 - Synolakis, C.E., Bernard, E.N., Titov, V.V., Kânoğlu, U.T.K.U. and Gonzalez, F.I., 2008. Validation and verification of tsunami numerical models. In: Tsunami science four years after the 2004 indian ocean tsunami (pp. 2197-2228). Birkhäuser Basel.

- Tanioka, Y. and Satake, K., 1996. Tsunami generation by horizontal displacement of ocean bottom. Geophysical research letters, 23(8), pp.861-864.

450 - Titov, V.V., Mofjeld, H.O., González, F.I. and Newman, J.C., 1999. Offshore forecasting of Hawaiian tsunamis generated in Alaskan-Aleutian subduction zone. NOAA Technical Memorandum ERL PMEL, 114, p.22.

- Titov V, Kânoğlu U, Synolakis C (2016) Development of MOST for real-time tsunami forecasting. J Waterw Port Coast Ocean Eng 142:03116004-1-03116004-16

455 - Titov, V.V. and Synolakis, C.E., 1998. Numerical modeling of tidal wave runup. Journal of Waterway, Port, Coastal, and Ocean Engineering, 124(4), pp.157-171.

- Umino, N., Kono, T., Okada, T., Nakajima, J., Matsuzawa, T., Uchida, N., Hasegawa, A., Tamura, Y. and Aoki, G., 2006. Revisiting the three M-7 Miyagi-oki earthquakes in the 1930s: possible seismogenic slip on asperities that were re-ruptured during the $1978 \mathrm{M}=$ 4607.4 Miyagi-oki earthquake. Earth, planets and space, 58(12), pp.1587-1592.

- Wessel, P. and Smith, W.H., 1998. New, improved version of Generic Mapping Tools released. Eos, Transactions American Geophysical Union, 79(47), pp.579-579.

- Yokota, Y., Ishikawa, T., Watanabe, S.I., Tashiro, T. and Asada, A., 2016. Seafloor geodetic constraints on interplate coupling of the Nankai Trough megathrust zone. Nature, 534(7607), pp.374-377. 